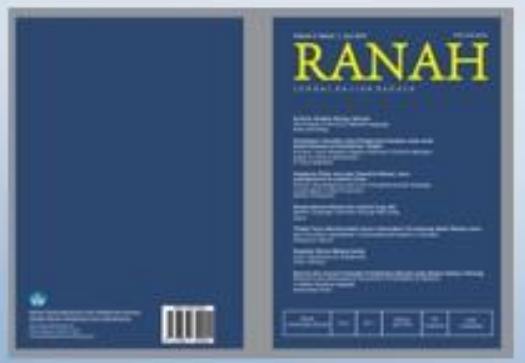

Ranah: Jurnal Kajian Bahasa

http://ojs.badanbahasa.kemdikbud.go.id/jurnal/index.php/jurnal_ranah

p-ISSN: 2338-8528

e-ISSN: $2578-8111$

\title{
ANALISIS WACANA KRITIS CUITAN FAHRI HAMZAH (FH) TERKAIT HAK ANGKET KOMISI PEMBERANTASAN KORUPSI (KPK)
}

Critical Discourse Analysis of Fahri Hamzah's (Fh's) Nudge on The Right of Inquiry of Corruption Eradication Commision (KPK)

\author{
Ali Kusno dan Nur Bety \\ Kantor Bahasa Kalimantan Timur \\ Pos-el: alikusnolambung@gmail.com; bety_salim@yahoo.com
}

Naskah Diterima Tanggal 18 September 2017-Direvisi Akhir Tanggal 20 November 2017 —Disetujui Tanggal 28 November 2017 doi: https://doi.org/10.26499/rnh.v6i2.462

\begin{abstract}
Abstrak
Fahri Hamzah (FH) merupakan salah satu pimpinan di DPR yang sering mengkritisi Komisi Pemberantasan Korupsi (KPK) melalui akun Twitter-nya. Salah satunya adalah masalah pengajuan hak angket KPK. Penelitian ini akan mengungkapkan persepsi FH melalui cuitan di Twitter pada tanggal 2-26 Juli 2017. Pengungkapan persepsi tersebut dianalisis menggunakan model Fairclough. Hasil penelitian berdasarkan analisis tekstual (analisis mikro) menunjukkan bahwa struktur teks pendek dan langsung menyampaikan isi tuturan. Adapun secara substansi teks mengungkapkan beragam persepsi FH, seperti masyarakat disuguhi drama tentang KPK, KPK selalu dianggap benar, dan media berlaku tidak objektif. Aspek ketransitifan menunjukkan FH menguatkan hal-hal negatif dan meniadakan hal positif. Terdapat penekanan tentang kebobrokan KPK. Fungsi modalitas berupa tuturan yang menguatkan perlunya Pansus Angket KPK. Penggunaan kosakata secara keseluruhan menggambarkan pandangan negatif dan pesimisme terkait kinerja KPK. Penggunaan gaya bahasa sinisme, sarkasme, dan satire mewarnai keseluruhan cuitan FH. Analisis berdasarkan dimensi praktik wacana (level menengah) menunjukkan bahwa pandangan FH berseberangan dengan opini publik. Pansus KPK dianggap sebagai upaya melindungi anggota DPR yang terlibat kasus e-KTP. Adapun analisis berdasarkan dimensi praktik sosial budaya (level makro) menunjukkan bahwa FH termasuk politisi yang sering mengkritik kinerja KPK, termasuk penanganan kasus e-KTP.
\end{abstract}

Kata kunci: persepsi, analisis wacana kritis, hak angket KPK

\begin{abstract}
Fahri Hamzah (FH) is one of the leaders in parliament who often criticizes the Corruption Eradication Commision (KPK) through his Twitter account. One of them is the submission of the right of inquiry of KPK. This study will reveal the perception of FH through his tweet on July, 2-26, 2017. The perception disclosure is analyzed using the Fairclough model. Research content based on the textual analysis (micro analysis) shows that the text structure is short and directly convey the content of the speech. Substantially, the text reveals various
\end{abstract}


perceptions of $F H$, such as the people treated to drama about KPK, KPK is always considered true and the media is not objective. The transitive aspect indicates that FH reinforces negative things and negates positive things. There is an emphasis on the wrack of $K P K$. The modalities function is in the form of a speech that strengthens the need for special committee's of the right of inquiry of KPK. The use of vocabulary overall illustrates the negative opinion and pessimism related to the performance of the KPK. The use of cynicism, sarcasm and satire styles colors the entire FH's tweets. The analysis based on the dimension of discourse practice (meso-level) indicates that FH's views are contrary to the public opinion. The Special Committee of KPK is considered as an effort to protect the members of parliament who are involved in e-KTP case. The analysis based on the social cultural practice dimension (macro-level) indicates that $F H$ is one of the politician who often criticizes the performance of KPK, including the handling of e-KTP case.

Keywords: perception, critical discourse analysis, right of inquiry of KPK

How to Cite: Kusno, Ali dan Nur Bety. (2017). Analisis Wacana Kritis Cuitan Fahri Hamzah (Fh) Terkait Hak Angket Komisi Pemberantasan Korupsi (KPK). Ranah: Jurnal Kajian Bahasa, 6 (2), 137-159. doi: https://doi.org/10.26499/rnh.v6i2.462

\section{PENDAHULUAN}

Dewan Perwakilan Rakyat (DPR), sebagai lembaga legislatif, telah mengajukan hak angket Komisi Pemberantasan Korupsi (KPK). Pengajuan angket salah satunya didasari pertimbangan untuk perbaikan KPK. Namun, upaya tersebut banyak mendapat penentangan dari berbagai kalangan masyarakat Indonesia. Jerry Sumampouw, pengamat politik dari Komite Pemilih Indonesia dan juga anggota Koalisi Masyarakat Sipil Tolak Angket KPK menilai bahwa alasan penggunaan hak angket untuk membenahi dan mengawasi KPK tidak kuat. Ada mekanisme lain yang dapat digunakan oleh DPR untuk memperbaiki kinerja KPK, yakni rapat dengar pendapat dan rapat konsultasi untuk membenahi kelemahan KPK. Anggaran untuk penggunaan hak angket KPK mencapai 3,1 miliar rupiah. Masih banyak jalan untuk membenahi KPK daripada melalui hak angket (Erdianto, 2017). Hal yang sama juga diungkapkan peneliti dari Forum Masyarakat Peduli Parlemen Indonesia (Formappi), yaitu Lucius Karus, yang menganggap Pansus KPK ingin sebisa mungkin mencegah KPK semakin dekat dengan DPR.

Fahri Hamzah (FH) selaku pimpinan DPR menyatakan pansus tetap harus menjalankan tugasnya tanpa harus khawatir dicemooh oleh pihak yang kontra. Sementara itu, Ketua Panitia Angket KPK, Agun Gunandjar menegaskan hak angket merupakan hak DPR untuk mengadakan penyelidikan mengenai masalah tertentu. Fungsi ini diatur dalam 
konstitusi. Agun Gunandjar menilai bahwa masih banyak orang yang membutuhkan penjelasan tentang angket. Hak angket adalah hak konstitusional dewan yang dijamin konstitusi, sebagai hak penyidikan tertinggi dalam konteks negara (Hakim, 2017).

Salah satu anggota DPR yang paling getol mengusung hak angket KPK adalah FH. Menurut FH, salah satu alasan dibentuknya Pansus Hak Angket KPK karena KPK dianggap berpolitik. Selain itu, keanehan lain yang selama 15 tahun pendirian KPK selalu ditutuptutupi dan tidak pernah diungkap ke publik. Bahkan saat keanehan ini akan diungkap melalui pansus angket, justru KPK tampak ketakutan ("Fahri Hamzah: Ungkap Keanehan di Tubuh KPK," 2017).

Dalam berbagai kesempatan, baik berbicara maupun melalui media, FH banyak menyerang KPK. FH sering melancarkan kritikan terhadap KPK melalui media sosial, seperti Twitter. FH termasuk politisi yang sering menanggapi berbagai persoalan politik dan lainnya melalui media sosial Twitter, termasuk menanggapi persoalan Pansus Angket KPK. Oleh karena itu, sangat penting mengkaji cuitan FH dalam akun Twitter untuk mengungkapkan persepsi FH terkait dengan hak angket KPK. Oleh karena itu, dalam penelitian ini dianalisis tentang persepsi FH terkait hak angket KPK yang diidentifikasi berdasarkan unggahan FH di akun Twitter-nya. Persepsi itulah yang menjadi salah satu indikator latar belakang DPR mengajukan hak angket terhadap KPK. Selain itu, untuk memahami persoalan berkaitan dengan KPK secara komprehensif dari sisi pandangan DPR dan pandangan publik.

\section{LANDASAN TEORI}

Menurut Kamus Besar Bahasa Indonesia (2014:1061) persepsi adalah tanggapan (penerimaan) langsung dari sesuatu; serapan, proses seseorang mengetahui beberapa hal melalui pancaindranya. Selain itu, persepsi juga bermakna tindakan menyusun, mengenali, dan menafsirkan informasi sensoris untuk memberikan gambaran dan pemahaman tentang lingkungan. Oleh karena itu, dapat disimpulkan persepsi merupakan suatu proses pengindraan, stimulus yang diterima oleh individu melalui alat indra yang kemudian diinterpretasikan sehingga individu dapat memahami dan mengerti tentang stimulus yang diterimanya tersebut. 
Persepsi FH tentang Pansus Angket KPK dapat diungkapkan melalui wacana cuitan FH di Twitter. Menurut Purbani (2009:1), wacana memiliki pengertian yang beragam tergantung pada konteks apa yang tengah digunakan untuk memperbincangkannya. Secara umum wacana dipahami sebagai pernyataan-pernyataan. Dalam ranah lingusitik, wacana dipahami sebagai unit kebahasaan yang lebih besar daripada kata atau kalimat, yang dapat melibatkan satu atau lebih orang. Jadi, sebuah pidato, dialog, polemik, perdebatan, dan percakapan dapat dikategorisasikan sebagai sebuah wacana.

Istilah wacana yang digunakan dalam analisis wacana kritis (critical discourse analysis) salah satunya dikembangkan ahli linguistik sosial, seperti Norman Fairclough. Analisis wacana kritis model Fairclough menempatkan wacana atau penggunaan bahasa sebagai praktik sosial; wacana atau penggunaan bahasa dihasilkan dalam sebuah peristiwa diskursif tertentu; wacana yang dihasilkan berbentuk sebuah genre tertentu (Ahmadi, 2014:255). Eriyanto (2015:286) memandang bahasa sebagai praktik sosial, mengandung sejumlah implikasi. Pertama, wacana adalah bentuk dari tindakan, seseorang menggunakan bahasa sebagai suatu tindakan pada dunia dan khususnya sebagai bentuk representasi ketika melihat realitas. Kedua, model mengimplikasi adanya hubungan timbal balik antara wacana dan struktur sosial.

Analisis wacana kritis model Fairclough dikenal dengan sebutan analisis wacana tiga dimensi. Analisis tiga dimensi ini ialah analisis yang mengintegrasikan tiga level analisis, yaitu 1) analisis tekstual (level mikro) adalah analisis deskriptif terhadap dimensi teks; 2) analisis praktik wacana (level meso) adalah analisis interpretatif terhadap pemroduksian, penyebaran, dan pengonsumsian wacana, termasuk intertekstualitas dan interdiskursivitas; dan 3) analisis sosiokultural (level makro) adalah analisis eksplanatif terhadap konteks sosiokultural yang melatarbelakangi kemunculan sebuah wacana (Fairclough, 1995:57--62). Dengan menggunakan analisis tiga dimensi itu dapat diungkapkan pemaknaan sebuah wacana dengan lebih menyeluruh dan mendalam.

\section{METODE PENELITIAN}

Metode yang digunakan dalam penelitian ini adalah metode penelitian kualitatif yang bersifat deskriptif. Metode penelitian kualitatif merupakan prosedur penelitian yang 
menghasilkan data deskriptif berupa kata-kata tertulis dan lisan tentang sifat individu, keadaan, gejala dari kelompok tertentu yang dapat diamati (Moleong, 1994:6). Objek penelitian ini adalah penggunaan bahasa dalam cuitan FH dalam media sosial Twitter. Data dan sumber data yang digunakan dalam penelitian ini berupa dokumen. Sumber data dokumen, yaitu cuitan FH dalam media sosial Twitter periode 2 Juli sampai dengan 26 Juli 2017 pada saat situasi politik nasional sedang memanas terkait pengajuan hak angket KPK. Penelitian ini menggunakan kajian analisis wacana. Prinsip penafsiran (Djajasudarma, 1993:75) dapat terjadi melalui penafsiran lokal (termasuk ruang dan waktu), dan prinsip analogi dalam menafsirkan pengertian (makna) yang terkandung dalam wacana. Dengan analisis wacana, dapat dipahami bahwa "... discourse a word that constructs language as active: texts and talks in social practice" (Hepburn dan Potter, 2007). Pengkajian data dilakukan dengan menginterpretasikan tanda dan makna pesan verbal, serta unsur dalam wacana cuitan FH dalam media sosial Twitter.

\section{PEMBAHASAN}

Analisis Wacana Kritis Model Fairclough meliputi tiga dimensi, yakni analisis tekstual (level mikro), analisis praktik wacana (level meso), dan analisis sosiokultural (level makro). Berikut ini analisis wacana kritis cuitan FH dalam akun Twitter yang diunggah selama tanggal 2-26 Juli 2017.

\section{Analisis Tekstual (Analisis Mikro)}

\section{Struktur Teks}

Struktur teks biasa dibagi menjadi tiga bagian, yaitu bagian pembuka, bagian isi, dan bagian penutup. Struktur teks cuitan FH secara umum tanpa menggunakan pembuka dan penutup. Tuturan dalam akun itu relatif pendek-pendek dengan langsung menyampaikan isi tuturan. Selanjutnya, secara substansi isi teks cuitan mengungkapkan beberapa hal yang dapat diidentifikasi sebagai persepsi $\mathrm{FH}$ yang berkaitan dengan pengajuan hak angket KPK. Berikut ini beragam persepsi FH berkaitan dengan hak angket KPK yang tertuang dalam cuitan Twitter. 


\section{Masyarakat disuguhi dengan drama tentang KPK}

Selama ini KPK dianggap menutup-tutupi proses penyidikan dan penyelidikan. Hal itu salah satu yang mendasari didorongnya hak angket terhadap KPK, seperti yang disampaikan FH dalam penggalan cuitan berikut ini.

(1) Menyerahlah kawan.. Waktunya sdh tiba ...

Berdasarkan data (1) FH meminta kawan (KPK) untuk menyerah atau mau menerima hak angket KPK. Selama ini KPK begitu getol menolak hak angket karena dianggap dapat melemahkan KPK. Termasuk tanggapan FH terhadap adanya pemberitaan yang memberitakan KPK: Orang Waras Bisa Nilai Pernyataan Saksi Pansus Angket. Hal yang sama disampaikan FH dalam cuitan di Twitter berikut.

(2) Bahwa kebenaran, meski pahit seperti empedu. Tetap harus dikatakan dengan merdu. Semoga....

Berdasarkan data (2) FH berpandangan pengajuan hak angket KPK merupakan bagian dari upaya DPR untuk mengungkapkan kebenaran yang selama ini ditutup-tutupi KPK. DPR berharap upaya hak angket KPK dapat membuka pandangan masyarakat atas segala kebohongan fakta yang selama ini ditutup-tutupi. Pandangan serupa juga diungkapkan FH dalam cuitan berikut ini.

(3) Mari kita doakan agar semua kerja \#PansusAngketKPK Dan kesaksian yg ada membuka mata bangsa kita.

Berdasarkan data (3) FH mengajak bangsa Indonesia untuk bersama-sama berdoa menunjang kinerja Pansus Angket KPK. Berbagai kesaksian yang diungkap dalam Pansus Angket KPK dapat membuka pandangan bangsa Indonesia. FH dalam unggahan tersebut berpandangan bahwa KPK selama ini seolah menutupi segala fakta yang sebenarnya. Pansus KPK bertujuan untuk membuka fakta bahwa KPK menyimpan banyak kebobrokan. Upaya membuka segala kejelekan KPK itulah yang sedang dijalankan oleh Pansus Angket KPK. Dalam cuitan berikut ini FH kembali mengungkapkan hal serupa.

(4) Dan dengan kelurusan niat itu akhirnya tersingkaplah tabir dusta dan kebohongan orang2 yang palsu. \#SaveYulianisDkk

Berdasarkan data (4) FH mengungkapkan berbagai upaya pemanggilan saksi dilakukan DPR untuk mencari kebenaran yang selama ini ditutup-tutupi. Apa yang dilakukan panitia 
angket KPK tidak lain untuk mengungkap kebohongan yang selama ini berlangsung demi menutupi segala kebobrokan KPK. FH pun meyakinkan khalayak bahwa upaya Pansus Angket KPK untuk mengungkapkan kebohongan orang-orang yang palsu (di lingkungan KPK). Orang-orang yang palsu yang dimaksud adalah para anggota dan unsur pimpinan KPK.

Berdasarkan analisis data (1) sampai dengan (4) FH berpandangan selama ini masyarakat dihadapkan dengan banyak kebohongan tentang KPK. FH meminta KPK untuk menerima hak angket KPK. Selama ini KPK dianggap menolak hak angket karena dapat melemahkan KPK. FH berpandangan pengajuan hak angket KPK merupakan bagian dari upaya DPR untuk menyampaikan kebenaran yang selama ini ditutup-tutupi KPK. DPR berharap upaya hak angket dapat membuka pandangan masyarakat atas segala kebohongan fakta yang selama ini ditutup-tutupi KPK.

FH mengungkapkan berbagai upaya pemanggilan saksi dilakukan DPR untuk mencari kebenaran yang selama ini ditutup-tutupi KPK. Apa yang dilakukan panitia angket KPK tidak lain untuk mengungkap kebohongan yang selama ini berlangsung menutupi kebobrokan KPK. Bahkan FH pun meyakinkan khalayak bahwa upaya panitia angket KPK untuk mengungkapkan kebohongan orang-orang yang palsu. Orang-orang palsu yang dimaksud adalah para anggota dan unsur pimpinan KPK.

\section{KPK selalu dianggap benar}

Selama ini masyarakat menilai bahwa kinerja yang dilakukan oleh KPK sudah tepat dan benar. Masyarakat memiliki harapan yang besar terhadap KPK agar dapat memberantas korupsi di Indonesia, baik skala yang besar maupun kecil di tingkat pusat dan daerah. Sudah banyak pejabat dan politisi yang ditangkap KPK karena kasus korupsi. Oleh karena itu, masyarakat menilai jika KPK merupakan lembaga yang benar dan bersih. Di tengah maraknya kasus karupsi, KPK mampu membongkar kasus-kasus korupsi yang terjadi di Indonesia. Berbagai aksi KPK tersebut meraih simpati masyarakat. Sebaliknya, FH beranggapan bahwa tindakan yang dilakukan oleh KPK tersebut tidak selalu benar. Menurut FH, pandangan atau anggapan masyarakat seperti itu harus dikoreksi. Hal itu terlihat dalam cuitan FH sebagai berikut. 
(5) Tampil di bawah sumpah mengoreksi KPK yg telah jadi berhala bagiku tidaklah mudah... tapi resiko itu dia ambil..

Berdasarkan data (5) FH berusaha menarik simpati publik telah bekerja di bawah sumpah. FH beranggapan sebuah risiko mengoreksi KPK karena KPK selama ini dianggap selalu benar tanpa memiliki cela. Bahkan menurut FH, bangsa Indonesia selama ini terkesan memperlakukan KPK, seperti berhala. KPK diperlakukan layaknya Tuhan oleh masyarakat Indonesia. KPK dianggap tidak memiliki cela sedikit pun. Hal yang sama juga diungkapkan FH dalam cuitan Twitter berikut ini.

(6) kesaksian, Pastilah membuka sedikit kelopak mata atau hati yang tertutup lama oleh dusta...

Pada data (6) FH mengungkapkan beberapa kesaksian yang dipanggil Pansus Hak Angket KPK pastilah membuka pandangan masyarakat yang selama ini ditutupi kebohongan KPK. FH beranggapan KPK selama ini telah banyak berdusta kepada masyarakat Indonesia.

Berdasarkan data (5) dan (6) dapat dipahami bahwa FH menuding adanya anggapan KPK selalu dianggap benar. FH berusaha menarik simpati publik bahwa dirinya telah bekerja di bawah sumpah. FH beranggapan sebuah risiko mengoreksi KPK karena KPK selama ini dianggap selalu benar tanpa cela. Bahkan, menurut FH, bangsa Indonesia selama ini terkesan memperlakukan KPK layaknya Tuhan. KPK dianggap tidak memiliki cela sedikit pun. FH juga mengungkapkan beberapa kesaksian yang dipanggil Pansus Angket KPK pastilah membuka pandangan masyarakat yang lama tertutup oleh dusta KPK. FH beranggapan KPK selama ini telah banyak berdusta kepada masyarakat Indonesia.

\section{Media berlaku tidak objektif}

Pemberitaan tentang KPK selalu menarik perhatian masyarakat. Begitu pula berbagai kasus penangkapan selalu menjadi berita utama di berbagai media cetak dan elektronik. Pemberitaan media terhadap KPK itu membuat FH berpandangan media berlaku tidak objektif. FH beranggapan media selama ini dianggap mendukung KPK dan menolak hak angket KPK, seperti dalam cuitan FH berikut ini.

(7) Saya berharap media berlaku adil kepadanya...tetapi jika tidak, @yulianis13450 nampaknya telah siap untuk menghadapinya. 
Berdasarkan data (7) FH mengungkapkan harapannya agar media dapat berlaku adil terkait pemberitaan tentang KPK dan Pansus Hak Angket KPK. Menurut FH media massa seolah memberikan dukungan terhadap KPK tanpa memberikan informasi berimbang terkait Hak Angket KPK.

\section{KPK berlaku tebang pilih}

Penanganan kasus korupsi banyak menyasar pejabat-pejabat publik yang juga orang-orang yang berpolitik. Oleh karena itu, risiko terjadi konflik kepentingan sangat besar. Selain itu, anggota-anggota KPK berpeluang menjadikan politisi dan pejabat sebagai tersangka pundi-pundi kejahatan.

(8) \#PansusAngketKPK\#AmienRaisBicara Melawan Lupa... RMOL.COAkun terverifikasi@ @rmolco25 Jul. Akan Kembalikan Uang RS Sumber Waras, Bukti KPK Tebang Pilih \#KPK

Berdasarkan data (8) FH mengungkapkan adanya tersangka dalam kasus Sumber Waras yang dianggap tidak diatasi dengan baik oleh KPK. Hal ini merupakan ironi atau sindiran terhadap KPK yang dinilai tidak adil terhadap dugaan korupsi di kasus Sumber Waras Jakarta. Kasus Sumber Waras berawal dari temuan Badan Pemeriksa Keuangan (BPK) mengenai kasus pembelian lahan RS Sumber Waras oleh Pemerintah Provinsi DKI Jakarta.

\section{Ironi KPK yang katanya bersih}

Aksi dan citra yang dibangun terhadap KPK memang mempersepsikan bahwa KPK sebagai lembaga yang bersih bebas korupsi. KPK selama ini dianggap masyarakat sebagai lembaga yang selalu tampil bersih. Hal itu dianggap sebagai upaya pencitraan, seperti diungkapkan FH dalam cuitan Twitter berikut ini.

(9) FAHRI HAMZAH me-Retweet VIVAcoid Malaikat kok makan uang?

FAHRI HAMZAH menambahkan, VIVAcoidAkun terverifikasi @VIVAcoid Yulianis: Komisioner KPK Terima Uang Nazar 1 Miliar http://dlvr.it/PY3zFY

Berdasarkan data (9) FH mempertanyakan adanya dugaan komisioner KPK yang menerima suap. Hal itu didasarkan pengakuan salah satu saksi kunci KPK yang dipanggil Pansus Angket KPK. Hal itu juga diungkapkan FH dalam cuitan berikut ini. 
(10) FAHRI HAMZAH me-Retweet TEMPO.CO

Cukuplah TEMPO dan KPK....

FAHRI HAMZAH menambahkan,

TEMPO.COAkun terverifikasi @ tempodotco

Patrialis Akbar Banjiri Anggita Hadiah: Mobil, Pakaian, Dollar...

Berdasarkan data (10) FH mengungkapkan adanya ironi KPK yang bersih dan aman. FH berpersepsi KPK tidak sepenuhnya bersih dan perlu diungkapkan segala kebobrokannya. FH juga menyoroti perlakuan KPK terhadap tersangka korupsi lain, seperti dalam cuitan berikut ini.

(11) FAHRI HAMZAH me-Retweet TEMPO.CO Ini kelakuan KPK... FAHRI HAMZAH menambahkan, TEMPO.COAkun terverifikasi @ tempodotco Patrialis Sempat Ajak Anggita Lihat Rumah sebelum Ditangkap KPK

Berdasarkan data (11) tersebut FH mengkritik KPK dalam penangkapan Anggita sebelum ditangkap. Berdasarkan data (12) dan (13), FH menyoroti hal tersebut dan menganggap KPK tidak selamanya bersih. Terlebih lagi Ketua KPK dituduh terlibat dalam kasus E-KTP yang sedang ramai diusut oleh KPK sendiri. Dalam hal ini FH menganggap adanya konflik kepentingan. FH juga menyoroti perlakuan KPK terhadap tersangka korupsi lain.

\section{KPK seolah tidak percaya diri}

Pada bulan Juli KPK melakukan operasi tangkap tangan. Hal itu rupanya tidak luput dari perhatian FH, seperti yang diungkapkan dalam cuitan berikut.

(12) Barusan tersangka apa lagi itu @KPK_RI? Kayak gak PD.

Berdasarkan data (12) FH mempertanyakan hasil tangkapan KPK tersebut terkait kasus apa. FH menuding KPK tidak percaya diri. Berbagai aksi tangkap tangan yang dilakukan KPK memberikan gambaran bahwa KPK tidak percaya diri.

\section{Ketua KPK terlibat konflik kepentingan}

Ketua KPK diangap terlibat dalam kasus E-KTP. Hal itu merupakan bentuk konflik kepentingan, seperti diungkapkan FH dalam cuitan Twitter berikut ini. 
(13) FAHRI HAMZAH me-Retweet Furqan Jurdi

KPK tutup telinga...

FAHRI HAMZAH menambahkan,

Furqan Jurdi @furqanjurdi

Mari Kita Urai dugaan Keterlibatan ketua @KPK_RI dalam kasus E-KTP. dengan terlebih dahulu memberikan 10 Pertanyaan Bang@Fahrihamzah

Berdasarkan data (13) FH menuduh Ketua KPK terlibat dalam kasus E-KTP yang sedang ramai diusut oleh KPK sendiri. Terhadap dugaan tersebut, KPK terkesan menutup telinga karena memang terdapat konflik kepentingan dalam tubuh KPK.

\section{KPK menyalahgunakan kewenangan}

KPK sebagai lembaga antikorupsi memiliki beragam kewenangan dalam mengungkap dan menindak kasus korupsi. Salah satunya kewenangan KPK untuk melakukan penyadapan. FH sering mengkritik KPK karena dianggap menyalahi kewenangannya seperti dalam cuitan Twitter FH berikut.

(14) FAHRI HAMZAH me-Retweet romli atmasasmitaSaya sedih prof... Kasus KPK terulang.. Kewenangan represif selalu disalahgunakan.. Itu kata lord acton. FAHRI HAMZAH menambahkan,romli atmasasmita@rajasundawiwaha polri tdk hrs mencari2 anggota HTI sampai ke kampus 2 ckp awasi sj jika perpu dilanggar baru ditindak

Berdasarkan data (14) FH mempersoalkan KPK karena sudah berkali-kali melakukan kesalahan dengan menyalahgunakan kewenangan represif. FH juga mengkritik KPK terkait penanganan kasus Rumah Sakit Sumber Waras dengan mengunggah cuitan berikut.

(15) FAHRI HAMZAH me-Retweet Sementara itu KPK menyerang BPK... FAHRI HAMZAH menambahkan, Ada yg. mau balikin duit ya? Jd. bener kan soal RSSW? "Knp. ada kerugian negara? Penyimpangannya...

Berdasarkan data (15) FH berpandangan KPK selama ini menyerang BPK yang membuka temuan adanya kerugian negara akibat kasus Sumber Waras. Sementara itu, ada yang mau mengembalikan kerugian negara akibat kasus Sumber Waras. Oleh karena itu, dapat dipahami bahwa FH menuding KPK karena sudah berkali-kali melakukan kesalahan dengan menyalahgunakan kewenangan represif. 


\section{KPK berlaku jahat dan zalim}

Dalam mengungkap berbagai kasus korupsi, KPK telah berhasil memenjarakan sekaligus menyita aset-aset terkait kasus korupsi dan penyuapan. Sebagian pihak menganggap tindakan KPK sebagai sebuah kejahatan dan kezaliman. Hal itulah yang ikut mendasari pengajuan Hak Angket KPK. Berikut ini unggahan FH yang menyinggung tentang perlakuan jahat dan zalim KPK.

(16) FAHRI HAMZAH me-Retweet Rio Ramabaskara Istilah ceroboh itu eufemisme..yg benar KPK zalim dan jahat kepada @anasurbaningrum..

Berdasarkan data (16) FH menganggap KPK zalim dan jahat, seperti dalam penanganan kasus Anas Urbaningrum. Tudingan serupa juga terdapat dalam cuitan Twitter FH berikut.

(17) Saya senang karena Hakim tipikor mulai kritis..ruang sidang harus dibersihkan dari fiksi dan mitos..Bapak Hakim Tipikor \#KasusEKTP telah membersihkan dakwaan@KPK_RI dari sampah...ini kelakuan mereka salama ini..

Berdasarkan data (17) FH merasa senang karena Hakim tipikor (tindak pidana korupsi) mulai kritis. Menurut FH ruang persidangan harus dibersihkan dari fiksi dan mitos. Fiksi dan mitos tersebut dapat dimaknai bahwa persidangan yang melibatkan KPK penuh dengan kebohongan. Menurut FH, hakim tipikor kasus E-KTP telah membersihkan dakwaan KPK dari berbagai hal yang tidak perlu.

\section{Jajaran KPK banyak masalah}

Salah satu hal yang menyebabkan pengajuan hak angket KPK karena adanya dugaan jajaran pimpinan KPK banyak masalah, seperti dalam cuitan FH berikut.

(18) Selamat istirahat pak ketua @KPK_RI semoga bapak sadar bahwa bapak juga banyak masalah. \#KasusEKTP

Berdasarkan data (18) FH berharap Ketua KPK menyadari bahwa dirinya banyak masalah. Hal yang sama juga terlihat dalam cuitan Twitter FH berikut.

(19) Tidak karena bapak bekerja di@KPK_RI tiba2 bapak jadi bersih dan tidak punya salah. Manusia sama saja. \#KasusEKTP 
Berdasarkan data (19) FH menyerang Ketua KPK yang dianggap memiliki catatan kriminal sehingga dengan masuk menjadi anggota KPK tidak menghilangkan catatan kasus tersebut. Hal itu juga diungkapkan dalam cuitan Twitter FH berikut.

(20) Bapak jangan sakit hati kalau saya bertanya sebab itu tugas setiap warga negara kepada aparat negara. \#KasusEKTP.Saya coba membaca biodata bapak dan jabatan bapak saat2 skandal ini terjadi rasanya perlu penjelas. \#KasusEKTPSebab kalau bapak terlibat dalam \#KasusEKTP ini maka tentu bapak tidak pantas lagi memimpin KPK. Bapak punya conflict of interest. Jujurlah bapak kepada bangsa ini..apakah betul bapak terlibat dalam \#KasusEKTP yang katanya mega korupsi itu?

Berdasarkan data (18)--(20) FH menyapa salah satu pimpinan KPK untuk tidak sakit hati sebab hal itu hak setiap warga negara kepada aparat negara. FH mempertanyakan adanya dugaan catatan skandal yang melibatkan salah satu pimpinan KPK. Menurut FH, apabila salah satu pimpinan tersebut terlibat dalam kasus E-KTP sehingga tidak pantas lagi memimpin KPK.

\section{Penangkapan tersangka baru merupakan upaya KPK untuk menghibur rakyat}

\section{Indonesia}

KPK sering melakukan operasi tangkap tangan (OTT), baik terhadap pelaku korupsi maupun penyuapan. FH menuduh KPK memiliki motif-motif tertentu dalam penentuan tersangka baru. Berikut cuitan FH tentang penangkapan KPK.

(21) Tersangka baru untuk menghibur publik...luar biasa...(Tutup Fakultas Hukum).FAHRI HAMZAH menambahkan,METRO TVAkun terverifikasi @Metro_TV [Popular] KPK Pastikan Tersangka Baru KTP-el tak Mengecewakan Publik http://metrotvn.ws/ybJeDwBN Tersangka baru untuk menghibur publik...luar biasa

Berdasarkan data (21) FH mengatakan penetapan tersangka baru merupakan upaya untuk menghibur publik dan tindakan yang luar biasa. Pernyataan tersebut merupakan sindiran untuk KPK dalam kinerjanya dalam pemberantasan korupsi lebih untuk mendapatkan simpati publik. 


\section{KPK berlaku untuk membentuk opini publik}

Selama ini pemberitaan seputar KPK sering menghiasi media massa. FH menganggap berbagai aksi yang dilakukan KPK selama ini tidak ubahnya sebagai upaya untuk membentuk opini publik.

(22) Pantas hukum ditegakkan dengan pamrih publik.. karena itulah cita2 kalian. Kalian adalah hamba opini bukan kebenaran hukum..FAHRI HAMZAH menambahkan,KPKAkun terverifikasi @KPK_RI Aksi dukungan Jurus Tandur Slank dan Koalisi Masyarakat Antikorupsi https://www.pscp.tv/w/bDXTmDc0MTkyOTd8MVJER2xtRURyWE9KTNvb9z7rwZUMYF8dsKYRnVK7Ng1kZa_Ai49Y60U_r1W ...

Berdasarkan data (22) FH berpandangan bahwa penegakan hukum oleh KPK untuk mendapatkan pamrih dari publik. FH menuding tujuan KPK hanyalah untuk membentuk opini publik bukan kebenaran publik.

(23) FAHRI HAMZAH me-Retweet detikcomPartai KPK bikin opini politik terus...mau ikut pilkada kali...

Berdasarkan data (23) FH menuding KPK membuat opini politik terus-menerus. FH berseloroh dengan memperkiraan aksi tersebut sebagai upaya KPK untuk mengikuti Pilkada.

\section{KPK sebagai alat cuci}

KPK selama ini memang menjadi lembaga yang disorot untuk melakukan pemberantasan korupsi di Indonesia. Sebagian tokoh politik menganggap KPK hanya menjadi lembaga untuk membersihkan nama seseorang atau oknum dari berbagai tindak kejahatan.

(24) FAHRI HAMZAH me-Retweet Hakim Alquds. KPK itu laundry... Lihat aja nanti...FAHRI HAMZAH menambahkan, Hakim Alquds @hakim_alquds Membalas @Fahrihamzah Bersihkan KPK dari oknum-oknum busuk... \#SaveKPK

Berdasarkan data (24) FH ikut berpandangan bahwa KPK sebagai alat cuci maksudnya membersihkan nama seseorang atau untuk menutupi jejak kriminal seseorang. Hal yang sama juga terdapat dalam cuitan Twitter FH berikut. 
(25) sy hadir meluruskan pendpt/kritik/sikap yg apriori pro KPK bukan u lemahkan atau hancurkan KPK, sy buka fakta seterang2nya dibwh sumpah!

Berdasarkan data (25) FH mengganggap hak angket merupakan upaya untuk membersihkan oknum-oknum KPK yang dinilai memiliki catatan kejahatan dan potensi terhadap kejahatan.

\section{Adanya pemerasan dalam KPK}

FH menganggap upaya KPK membongkor kasus-kasus yang ada merupakan upaya untuk mengeruk keuntungan dengan melakukan pemerasan. Berikut ini cuitan Twitter FH yang menuding oknum KPK melakukan pemerasan.

(26) FAHRI HAMZAH me-Retweet TEMPO.COIni pembuktian ala debt collector ... Yg nyetor sudah aman...

Berdasarkan data (26) FH menuturkan adanya pembuktian ala debt collector bagi yang mau menyetor (menyuap) dijamin aman dan tidak diganggu gugat. Berikut cuitan Twitter FH yang menuding oknum KPK melakukan pemerasan.

(27) Entah dengan siapa... Tetapi perang terjadi karena jalan hukum makin tidak terang...di sepanjang jalan banyak preman .. Tapi yang jelas, KPK telah hanya mengungkap satu versi dari peristiwa selama belasan tahun ini... \#SuaraRakyatSejati

Dalam cuitan tersebut, FH menuturkan perang terjadi karena jalan hukum makin tidak terang di sepanjang jalan banyak preman. Namun yang jelas, KPK telah mengungkap satu versi dari peristiwa selama belasan tahun ini. Berdasarkan data (26) dan (27) FH menuturkan adanya pembuktian ala debt collector bagi yang mau menyetor (menyuap) dijamin aman dan tidak diganggu gugat. Banyak preman yang membuat penegakan hukum makin sulit ditegakkan.

\section{KPK gagal dalam menjalankan fungsi}

Selama ini para politisi yang anti KPK menganggap KPK telah gagal menjalankan fungsinya, seperti cuitan Twitter FH berikut.

(28) FAHRI HAMZAH me-Retweet Tsamara Amany Kalau menurut saya sukses artinya ya koruptor habis..masalah selesai.. negara maju dan rakyat sejahtera.. 
(29) Ada yang bilang.. Karena tambah banyak KPK harus ada... Ada yang bilang kalau tambah banyak artinya gagal...bubarkan saja....!

(30) Ada yang bilang KPK gagal... Kok korupsi tambah banyak... Kok tidak makin hilang... \#SuaraRakyatSejati

Berdasarkan data (28)--(30) FH menuturkan makin maraknya kasus korupsi di Indonesia merupakan bentuk kegagalan KPK. Seharusnya KPK dapat membuat perubahan dengan semakin sedikit tingkat korupsi di Indonesia. Adapun faktanya saat ini, korupsi semakin banyak. Dengan demikian, KPK layak dibubarkan.

\section{Permainan KPK sudah berlangsung lama}

Sebagian politisi, termasuk FH, beranggapan telah berlangsung lama permainan KPK dalam penanganan kasus korupsi, seperti dalam cuitan Twitter FH berikut.

(31) Melawan lupa... KPK kerja apa? \#CenturyGateSaya mencium permainan KPK sejak lama..\#CenturyGate jangan lupa...

Ini berita jangan lupa... \#CenturyGate menguap di kPK...

Kemana.uangnya? Jangan lupa.... \#CenturyGate KPK tega..

Om ahmad.yani... Skandal2 besar yg ditutupi...

Keterangan pak.@Pak_JK Poltak KO... \#CenturyGate 6,7 Trilyun..

\#CenturyGate Jangan lupa Kesaksian..

KPK bilang ada pengembalian dana EKTP DARI BELASAN ORANG... Pertanyaan kok gak DITERSANGKAKAN?

KPK bilang ada bancakan dana EKTP oleh anggota DPR..... Ayo buktikan 1 saja...

Berdasarkan data (31) FH mengajak masyarakat Indonesia mengingat bahwa adanya dugaan permainan KPK sejak lama. Kasus lama, seperti Century Gate sebagai salah satu skandal yang ditutup-tutupi. FH juga mempertanyakan KPK terkait adanya pengembalian dana E-KTP dari belasan orang. FH juga mempertanyakan alasan orang-orang yang mengembalikan tersebut tidak ditersangkakan. FH juga mempertanyakan adanya pernyataan KPK tentang adanya korupsi besar-besaran E-KTP oleh anggota DPR. FH menantang KPK untuk membuktikan tuduhan tersebut.

\section{KPK melakukan kesalahan prosedur}

KPK dianggap menyalahi prosedur dalam melakukan kerjanya. Hal itu seperti yang diungkit-ungkit oleh pihak-pihak yang mengkritisi KPK. Berikut ini unggahan Fahri Hamzah yang menyinggung tentang hal itu. 
(32) Mahfud MD @mohmahfudmd KPK keliru. Tak ada mekanisme mempersilahkan penegak hukum lain klo sdh ditangani KPK. Klo mau, KPK resmi melimpahkan dan menyupervisinya. https://twitter.com/azkiya_lio/status/882412090735996928 ... FAHRI HAMZAH me-Retweet SITTOSaya ngerti kenapa pendukung ahok dukung KPK...tunggu waktu aja meledak..FAHRI HAMZAH menambahkan,SITTO @SittaYohag

Berdasarkan data (32) FH me-retweet ulang pernyataan Mahfud MD. Dengan demikian, FH sepakat dengan pernyataan Mahfud MD tersebut. Sesuai dengan pernyataan Mahfud MD, KPK telah melakukan kekeliruan. Tidak ada mekanisme mempersilakan penegak hukum lain kalau sudah ditangani KPK. KPK seharusnya resmi melimpahkan dan menyupervisinya.

\section{Penggunaan Gramatika Transitif}

Fairclough dalam Ahmadi (2014:257) mengemukakan analisis tekstual pada bagian tata bahasa memiliki tiga aspek yang dapat dianalisis, yakni ketransitifan, tema, dan modalitas. Aspek ketransitifan berkenaan dengan fungsi ideasional bahasa, aspek tema berkenaan dengan fungsi tekstual bahasa, sedangkan aspek modalitas berkenaan dengan fungsi interpersonal bahasa (Eriyanto dalam Ahmadi, 2014:257). Aspek ketransitifan dalam cuitan Twitter FH yang menunjukkan penutur menguatkan hal-hal negatif dan meniadakan hal positif terkait KPK. Terdapat penekanan terhadap banyak hal tentang kebobrokan lembaga anti korupsi KPK. Selanjutnya, fungsi modalitas dalam cuitan FH berupa tuturantuturan yang dapat menguatkan perlunya Pansus Angket KPK untuk membenahi segala kelemahan yang ada.

\section{Penggunaan Kosakata}

Unggahan cuitan Twitter FH secara keseluruhan menggambarkan pandangan negatif tentang KPK. Hal itu terlihat melalui penggunaan dan pilihan kata. Selain itu, tuturan dalam cuitan Twitter FH juga menggunakan bahasa yang bernuansa negatif dan pesimisme terkait kinerja KPK. Penggunaan gaya bahasa sinisme, sarkasme, dan satire mewarnai keseluruhan cuitan FH terkait kinerja KPK. 


\section{Dimensi Praktik Wacana (Level Meso)}

Menurut Fairclough (dalam Ahmadi, 2014:261), analisis praktik kewacanaan dipusatkan pada bagaimana teks diproduksi dan dikonsumsi, termasuk di dalamnya menelisik proses apakah yang dilalui suatu teks sebelum dicetak dan perubahan apa yang dialami sebelum disebarluaskan. Dimensi ini sangat bermanfaat untuk menggali latar belakang sebuah tuturan dan akibat tuturan tersebut. Teks cuitan Twitter FH merupakan gambaran sikap FH terhadap KPK. Pandangan FH tersebut merupakan gambaran yang melatarbelakangi pembentukan Pansus KPK oleh DPR. Hal itu berseberangan dengan opini publik yang beranggapan pembentukan Pansus KPK tidak lain merupakan upaya untuk melemahkan KPK. Pembentukan Pansus KPK bertepatan dengan penanganan KPK yang berkaitan dengan kasus E-KTP yang diduga melibatkan unsur pimpinan DPR dan anggota DPR. Pembentukan Pansus KPK dipandang sebagai upaya untuk melindungi anggota DPR yang terlibat dalam kasus E-KTP.

\section{Dimensi Praktik Sosial Budaya (Level Makro)}

Dalam dimensi sosial budaya dilakukan analisis eksplanatif terhadap konteks sosiokultural yang melatarbelakangi kemunculan sebuah wacana. FH termasuk politisi yang sering mengkritik kinerja KPK, termasuk penanganan kasus E-KTP. Oleh karena itu, FH termasuk pimpinan DPR yang mendesak adanya Pansus Angket KPK. Pandangan FH tersebut bertentangan dengan pandangan masyarakat. Selama ini masyarakat Indonesia sangat mendukung KPK dalam pemberantasan korupsi. Keberadaan KPK didukung masyarakat Indonesia karena menjadi harapan bagi pemberantasan korupsi di Indonesia. Korupsi dianggap menjadi salah satu penyebab bangsa Indonesia tidak maju. Anggaran pembangunan banyak dikorupsi. Masyarakat Indonesia begitu geram dengan maraknya korupsi di Indonesia. Oleh karena itu, ketika Pansus Angket KPK dibentuk, mendapat banyak penentangan dari masyarakat Indonesia.

Berdasarkan analisis tiga dimensi tersebut, dapat diambil beberapa pandangan FH terkait Pansus Angket KPK. FH beranggapan selama ini masyarakat disuguhi dengan kobohongan KPK. KPK selama ini selalu dianggap benar dan selalu bersih. Selama ini memang aksi dan citra yang terbangun di masyarakat memang seperti itu. Anggapan itu 
harus dikoreksi. Sebuah ironi KPK yang katanya bersih. Faktanya, KPK menyimpan banyak kebohongan selama ini.

Banyak fakta yang menunjukkan kebohongan dalam tubuh KPK. Kebohongan itu di antaranya, dugaan komisioner KPK menerima suap. Hal itu didasarkan pengakuan salah satu saksi kunci KPK yang dipanggil Pansus Angket KPK. Selain itu, adanya dugaan salah satu pimpinan KPK terlibat dalam kasus E-KTP yang sedang ditangani KPK sendiri. Hal itumenunjukkan adanya konflik kepentingan. KPK seolah menjadi sarana berlindung seseorang. Apabila benar terlibat dalam kasus E-KTP, pimpinan tersebut tidak pantas lagi memimpin KPK.

Dalam hal penindakan kasus korupsi, KPK terkesan berlaku tebang pilih. Penanganan kasus korupsi banyak menyasar pejabat publik yang juga tokoh politik. Risiko terjadi konflik kepentingan sangatlah besar. Anggota-anggota KPK berpeluang menjadikan tersangka sebagai pundi-pundi kejahatan. Upaya KPK membongkar kasus-kasus yang ada tidak lain merupakan upaya mengeruk keuntungan dengan melakukan pemerasan. FH menuturkan adanya pembuktian, seperti debt collector bagi yang mau menyetor (menyuap) dijamin aman dan tidak diganggu gugat. Adapun pada sisi lain, KPK terkesan melindungi pihak-pihak tertentu, seperti dalam penanganan kasus Sumber Waras.

Permainan KPK dalam menangani kasus sudah berlangsung lama. Kasus lama, seperti Century Gate sebagai salah satu skandal yang ditutup-tutupi KPK. FH juga mempertanyakan adanya pernyataan KPK tentang adanya korupsi besar-besaran E-KTP oleh anggota DPR. KPK harus mampu membuktikan tuduhan tersebut.

KPK jelas-jelas telah berlaku jahat dan zalim. Dalam mengungkap berbagai kasus korupsi, KPK telah berhasil memenjarakan sekaligus menyita aset-aset terkait kasus korupsi maupun penyuapan. Namun, dari sudut pandang pelaku, KPK zalim dan jahat seperti dalam penanganan kasus Anas Urbaningrum.

KPK juga telah menyalahgunakan kewenangan dan prosedur. Sebagai lembaga antikorupsi, KPK memiliki beragam kewenangan dalam mengungkap dan menindak kasus korupsi. Namun, KPK sudah berkali-kali melakukan kesalahan dengan menyalahgunakan kewenangan represif, seperti penanganan KPK terhadap kasus Rumah Sakit Sumber Waras. KPK selama ini menyerang BPK yang membuka temuan adanya kerugian negara akibat 
kasus Sumber Waras. Selain itu, KPK telah melakukan kekeliruan, seperti tidak adanya mekanisme yang mempersilakan penegak hukum lain apabila sudah ditangani KPK. Padalah, KPK seharusnya resmi melimpahkan dan menyupervisinya.

KPK seolah tidak percaya diri dalam menangani kasus korupsi, misalnya, pada bulan Juli KPK melakukan operasi tangkap tangan yang tidak jelas terkait dengan kasus apa. FH menuding berbagai aksi tangkap tangan yang dilakukan KPK memberikan gambaran bahwa KPK tidak percaya diri. FH beranggapan penangkapan tersangka baru merupakan upaya KPK untuk menghibur rakyat Indonesia. KPK sering melakukan operasi tangkap tangan (OTT) terhadap pelaku korupsi maupun penyuapan. FH menuduh KPK memiliki motif-motif tertentu dalam penentuan tersangka baru yang tidak lain untuk menghibur publik dan tindakan yang luar biasa. Pernyataan tersebut merupakan sindiran untuk KPK dalam kinerjanya, yaitu pemberantasan korupsi lebih untuk mendapatkan simpati publik.

Begitu banyak kebohongan KPK, opini publik justru berbeda. Hal itu dipengaruhi pemberitaan media yang berlaku tidak objektif. Media massa seolah memberikan dukungan terhadap KPK tanpa memberikan informasi berimbang terkait hak angket KPK. Media hendaknya dapat berlaku adil terkait pemberitaan tentang KPK dan Pansus Hak Angket KPK. Selan itu, KPK hanya membentuk opini publik bukan kebenaran publik.

Bagaimanapun juga, KPK harus tetap dikoreksi. Upaya mengoreksi KPK sebuah risiko karena berseberangan dengan opini publik. Hak angket KPK bertujuan untuk mengungkap kebohongan KPK dan tidak melemahkan KPK. KPK bukanlah lembaga yang selalu benar tanpa memiliki cela. Jangan sampai bangsa Indonesia memperlakukan KPK, seperti berhala yang dianggap tidak memiliki cela sedikit pun. Berbagai persoalan yang ada, menunjukan KPK telah gagal dalam menjalankan fungsinya. Fakta yang ada, kasus korupsi di Indonesia makin marak merupakan bukti kegagalan KPK. KPK seharusnya dapat membuat perubahan dengan semakin mengurangi tingkat korupsi di Indonesia. Berdasarkan fakta, saat ini korupsi makin banyak. Oleh karena itu, KPK layak dibubarkan.

Memang Panitia Khusus (Pansus) Hak Angket KPK telah mulai bekerja. Terkait hal itu, Presiden Jokowi telah menegaskan ingin agar KPK tidak dilemahkan. Lembaga KPK harus diperkuat dalam upaya pemberantasan korupsi. Presiden Jokowi tidak ingin KPK 
kendor karena negara Indonesia masih membutuhkan upaya-upaya yang luar biasa dalam pemberantasan korupsi. KPK harus lebih kuat agar menjadi landasan dalam upaya pemberantasan korupsi.

\section{PENUTUP}

Analisis wacana kritis model Fairclough terhadap unggahan FH dalam akun Twitter-nya memperlihatkan bahwa analisis tekstual (analisis mikro) menunjukkan struktur teks pendek dan langsung menyampaikan isi tuturan. Adapun secara substansi teks cuitan mengungkapkan beragam persepsi FH bahwa masyarakat disuguhi drama tentang KPK sebuah ironi yang katanya bersih, KPK selalu dianggap benar, media berlaku tidak objektif, KPK berlaku tebang pilih, KPK seolah tidak percaya diri, Ketua KPK terlibat konflik kepentingan, KPK menyalahgunakan kewenangan, KPK berlaku jahat dan zalim, jajaran KPK banyak masalah, penangkapan tersangka baru merupakan upaya KPK untuk menghibur rakyat Indonesia, KPK berlaku untuk membentuk opini publik, KPK sebagai alat cuci kepentingan, adanya pemerasan dalam KPK, KPK gagal dalam menjalankan fungsi, permainan KPK sudah berlangsung lama, KPK melakukan kesalahan prosedur. Selanjutnya, aspek ketransitifan menunjukkan bahwa penutur menguatkan hal-hal negatif dan meniadakan hal positif terkait KPK. Terdapat penekanan terhadap banyak hal tentang kebobrokan lembaga antikorupsi KPK. Selanjutnya, fungsi modalitas dalam cuitan FH berupa tuturan-tuturan yang dapat menguatkan perlunya Pansus Angket KPK untuk membenahi segala kelemahan yang ada. Penggunan kosakata dalam cuitan Twitter FH secara keseluruhan menggambarkan pandangan negatif tentang KPK. Hal itu terlihat melalui penggunaan dan pilihan kata. Selain itu, juga tuturan dalam cuitan Twitter FH menggunakan bahasa yang bernuansa negatif dan pesimisme terkait kinerja KPK. Penggunaan gaya bahasa sinisme, sarkasme, dan satire mewarnai keseluruhan cuitan FH terkait kinerja KPK.

Pada dimensi praktik wacana (level meso) memperlihatkan bahwa pandangan FH berseberangan dengan opini publik yang beranggapan pembentukan Pansus KPK tidak lain merupakan upaya untuk melemahkan KPK. Pembentukan Pansus KPK bertepatan dengan penanganan KPK yang berkaitan dengan kasus E-KTP yang diduga melibatkan unsur 
pimpinan DPR dan anggota DPR. Pembentukan Pansus KPK dipandang sebagai upaya untuk melindungi anggota DPR yang terlibat. Selanjutnya, dimensi praktik sosial budaya (level makro) memperlihatkan bahwa FH termasuk politisi yang sering mengkritik kinerja KPK, termasuk penanganan kasus E-KTP. Pandangan FH tersebut bertentangan dengan masyarakat. Selama ini masyarakat Indonesia sangat mendukung KPK dalam pemberantasan korupsi. Keberadaan KPK didukung karena menjadi harapan bagi pemberantasan korupsi di Indonesia. Korupsi dianggap menjadi salah satu penyebab bangsa Indonesia tidak maju. Anggaran pembangunan banyak dikorupsi. Masyarakat Indonesia begitu geram dengan maraknya korupsi di Indonesia. Oleh karena itu, ketika Pansus Angket KPK dibentuk, mendapat banyak penentangan.

Masyarakat dapat menilai wacana tuturan dalam cuitan Twitter FH sebagai bentuk dari tindakan. FH menggunakan bahasa sebagai suatu tindakan pada dunia dan khususnya sebagai bentuk representasi ketika melihat realitas tentang KPK. Media sosial, seperti Twitter banyak digunakan pejabat sebagai media untuk menyampaikan pesan dan pendapat kepada masyarakat. Masyarakat pun bisa menilai persepsi seorang pejabat melalui unggahannya di media sosial, seperti Twitter. Dengan penilaian yang menyeluruh terhadap pandangan politisi, termasuk yang disampaikan di media sosial, masyarakat diharapkan dapat berpikir kritis terhadap pandangan politisi. Masyarakat pun tidak akan lagi mudah dipermainkan dengan padangan politisi yang sering membingungkan.

\section{DAFTAR PUSTAKA}

Ahmadi F., Y. D. (2014). "Analisis Wacana Kritis: Ideologi Hizbut Tahrir Indonesia Dalam Wacana Kenaikan Harga BBM 2013 di Buletin Al-Islam yang berjudul 'Menaikkan Harga BBM: Nenaikkan Kemiskinan'.” Metalingua: Jurnal Penelitian Bahasa, 12 (2) (hlm. 253-265 .

Djajasudarma, T. F. (1993). Metode Linguistik: Ancangan Metode Penelitian dan Kajian. (W. Nadeak, Ed.) (I). Bandung: PT Eresco.

Erdianto, K. (2017, 8 Agustus). "Kenapa Memperbaiki Kinerja KPK Harus Lewat Hak Angket?" Diperoleh dari http://nasional.kompas.com/read/2017/07/14/20054151/kenapa-memperbaiki-kinerja-kpk-harus-lewat-hak-angket-.

Eriyanto. (2015). Analisis Wacana: Pengantar Analisis Teks Media. (N. Huda, Ed.). Yogyakarta: LKiS Yogyakarta.

Fairclough, N. (1995). Media Discourse. London: Edward Arnold.

Hakim, R. N. (2017, 26 Juli ). "Fahri Hamzah: Meski Semua Fraksi Keluar, Pansus Angket KPK Tetap Ada." Diperoleh dari http://nasional.kompas.com/read/2017/07- 
/26/13550251/fahri-hamzah--meski-semua-fraksi-keluar-pansus-angket-kpk-tetap-ada. Hamzah, Fahri.(2017, 8 Agustus). "Ungkap Keanehan di Tubuh KPK." (2017, 8 Agustus). Diperoleh dari http://www.beritametro.news/nasional/fahri-hamzah-ungkap-keanehandi-tubuh-kpk

Hepburn, A. dan Potter, J. (2007). "Discourse Analytic Practice." Dalam Seale, G.dkk. (Eds.), Qualitative Research Practice (II). Great Britain: Cromwell Press Ltd.

Moleong, L. J. (1994). Metodologi Penelitian Kualitatif. Bandung: PT Remaja Rosdakarya. Purbani, W. (2009). "Analisis Wacana Kritis dan Analisis Wacana Feminis." Diperoleh dari http://staff.uny.ac.id/system/files/pengabdian/dr-widyastuti-purbani-ma/analisiswacana-kritis.pdf. 